\title{
Traduire
}

Une autre perspective sur r tr traduction

Revue française de la traduction

$235 \mid 2016$

Luxe, mode... et traduction !

\section{«Il tacco a coda » : comment ne pas perdre pied avec ses talons}

Silvia Tallarida

\section{(2) OpenEdition}

1 Journals

Édition électronique

URL : https://journals.openedition.org/traduire/846

DOI : $10.4000 /$ traduire.846

ISSN : 2272-9992

Éditeur

Société française des traducteurs

Édition imprimée

Date de publication : 1 décembre 2016

Pagination : 54-55

ISSN : 0395-773X

Référence électronique

Silvia Tallarida, « « II tacco a coda » : comment ne pas perdre pied avec ses talons », Traduire [En ligne], 235 | 2016, mis en ligne le 01 décembre 2018, consulté le 06 juillet 2021. URL : http:// journals.openedition.org/traduire/846 ; DOI : https://doi.org/10.4000/traduire.846 


\section{" II tacco a coda " : comment ne pas perdre pied avec ses talons}

\section{Silvia Tallarida}

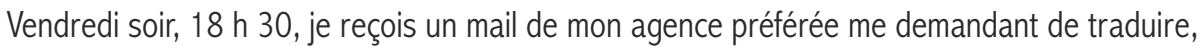
de l'italien vers le français, 7316 mots pour le lundi matin $11 \mathrm{~h}$.

Je consulte le document et constate que c'est encore pour cette grande marque de mode italienne que j'aime tant. Après une semaine passée à traduire des contrats commerciaux et des polices d'assurance, voilà qui va me changer les idées!

J'accepte donc le défi et l'idée de ne pas avoir de repos ce week-end-là.

II s'agit d'une formation en ligne destinée aux vendeurs, présentant la collection de chaussures et de sacs pour la saison à venir. Le fichier de travail est un simple document texte (avec des balises) déjà inséré dans le logiciel de TAO que j'utilise en ligne avec cette agence, sans aucune image pour me guider. Je dois donc rechercher sur le web des vidéos de collections de cette marque afin de me familiariser avec ses produits.

Au fil de la traduction, j'imagine la collection et lorsqu'un doute surgit, je visionne les vidéos, en italien, en français. Le souci est qu'il ne s'agit pas seulement d'énumérer des listes d'articles, mais bien d'expliquer toutes les étapes de leur fabrication : une manière de démontrer que seule une exécution spéciale avec des matériaux uniques donne un produit de luxe.

Et là, le monde du cuir, de la vannerie et de la maroquinerie s'offre à moi dans toute sa complexité.

Je découvre des vidéos illustrant le "foulonnage " du cuir, les types de coutures de sacs rendues invisibles par retournement, les techniques de broderie sur cuir propres à ce créateur, j'apprends à reconnaître les différentes parties d'une chaussure (eh oui, il n'y a pas que la semelle et le talon dans une chaussure !), et surtout je repère que, outre le talon bottier ou le talon aiguille, une multitude de noms existe pour désigner les innombrables sortes de talons. J'écume alors tous les lexiques possibles : de la chaussure, de la tannerie, de la maroquinerie, du textile, glossaire de la cordonnerie et des métiers du cuir... et découvre après deux jours 
de travail et de recherches acharnées que le fameux tacco a coda est tout simplement un " talon Louis XV".

Des expériences de ce type sont très intéressantes et très formatrices et c'est également ce saut dans l'inconnu qui rend le métier passionnant. Savoir rebondir, ne pas s'affoler malgré le temps qui passe et la traduction qui avance lentement. Traduire pour le luxe impose la perfection, plus encore que pour une traduction " standard ", d'autant plus que la traduction sera visible sur internet. Décrire la fabrication d'un sac de grande marque ne doit pas se faire de manière approximative, cela requiert autant de soin et de précision que le travail de l'artiste qui l'a réalisé.

Dans ces grands moments de solitude (week-end, nuit, délais trop courts) où les collègues ne sont pas actifs sur les forums pour vous dépanner immédiatement sur des termes aussi techniques, il faut prendre son mal en patience, savoir laisser le terme de côté afin de faire avancer la traduction et y revenir plus tard, à tête plus ou moins reposée.

Il est également certain que si le projet m'avait été confié directement par le client, j'aurais négocié un délai plus raisonnable, tenant compte des recherches à effectuer. C'est là que les conseils prodigués par les collègues plus chevronnés prennent toute leur importance : toujours prendre connaissance du document entier avant d'accepter le projet, histoire d'y déceler les pièges qu'on ne voit pas après une lecture en diagonale !!! Et l'éternelle question qui reste toujours posée : faut-il accepter les projets donnés par des agences qui ne laissent pas vraiment le choix du délai (et du tarif !) ou vaut-il mieux attendre (parfois longtemps) que les premiers clients directs nous fassent confiance et nous fassent vivre?

giuritec.traduzioni@gmail.com

Traductrice francophone freelance de l'italien et de l'anglais spécialisée dans les domaines juridique et technique, Silvia Tallarida est diplômée en commerce international et en langue italienne. De double culture franco-italienne, elle est de langue maternelle française. Ses compétences sont issues de sa formation linguistique et technique ainsi que d'une longue expérience de commerciale et de chargée d'administration des ventes à l'export dans des entreprises industrielles. Cette ancienne enseignante en italien a créé Giuritec Traduzioni en 2014 et a le statut d'entrepreneur auprès d'une coopérative. 